\title{
A HERMENÊUTICA COMO SABEDORIA PRÁTICA: \\ ENTRE GADAMER E RICOEUR
}

Luísa Portocarrero

Universidade de Coimbra

H-G.-Gadamer, o maior representante alemão da corrente hermenêtica do filosofar contemporâneo, procurou em toda a sua obra ultrapassar o dogmatismo da concepção moderna da ciência e de uma certa ideia de saber prático, o saber puramente pragmático, aquele que regido pelas leis da pura eficácia ainda hoje nos governa.

Lembra-nos, para isso, com base no mundo grego, que existiu uma outra ideia de sabedoria, a filosofia que nunca foi ciência, na acepção estrita em que esta palavra é hoje entendida pelas ciências positivas e especializadas e que dizia fundamentalmente respeito ao mundo da vida do humano. ${ }^{1}$ Isto é, à sua capacidade de viver a praxis de forma meditativa. A meditação filosófica não pode pois reduzir-se ao modelo de objectividade da ciência, tal é a tese que, na sequência de Husserl, o filósofo defende no conjunto de todos os seus escritos. Tese esta que o vai levar à defesa do carácter prático e hermenêutico do filosofar, socorrendo-se para isso do sentido mais envolvente do filosófico no mundo grego.

A filosofia ou sabedoria, lembra-nos, surgida da capacidade de espanto que o homem revela possuir, com o seu interesse por questões teóricas, i. é., por tudo aquilo que supera o mero desejo de conservação ou o âmbito do estritamente pragmático advertia já nesta altura para algo que o saber para fazer, característico dos nossos dias, tem camuflado. E que, no entanto, constitui o traço distintivo da condição humana : a necessidade de perguntar pelo sentido último das coisas, pela origem e finalidade do conhecimento e sobre-

1 H.-G. Gadamer, Vernunft im Zeitalter der Wissenschaft, Frankfurt, Suhrkamp, 1980, p. 110. 
tudo pelo significado da vida recta. ${ }^{2}$ Deste modo, ela correspondia à disposição natural do homem para a theoria que, no seu sentido originário, designava o interesse por o que transcende o útil, pelo belo ou paideia, o saber como fim em si mesmo, isto é, a cultura ou formação, capaz de instituir a solidariedade dos cidadãos votados à procura e realização do bem comum. Era neste sentido que a filosofia ela era considerada a primeira de todas as ciências em geral. Preocupava-se não só com o saber dos especialistas, mas fundamentalmente "com o saber geral na base do qual somos, e tomamos as nossas decisões práticas. [...], i.é, com o saber a respeito do bem comum."3

Ora, todos sabemos, que desde o séc. XVII esta concepção do filosófico se transformou decisivamente. E vivemos hoje, numa época em que o modelo grego de sabedoria foi completamente abandonado. Ou melhor, substituído pelo papel que a nova ciência - muito mais orientada para o poder agir com eficácia, do que para o saber viver em comum -, adquiriu nas sociedades. A própria filosofia seguiu, desde a Modernidade, o ideal metódico das ciências da natureza ou ciências experimentais, ideal que finalmente se impôs como o único modelo do saber.

Perdeu-se assim definitivamente, lembra-nos Gadamer, o que nos oferecia o antigo conceito de ciência: um saber integrador, uma forma mais geral do conhecer, que se procurava por si mesmo, repitamo-lo, pelas exigências da vida em comunicação e nunca pelos seus resultados pragmáticos.

A grande tradição da filosofia prática e política da Antiguidade - com todo o seu horizonte normativo fundamental, retomado com alguma força, mais tarde, pela problemática do humanismo e finalmente pelo horizonte das chamadas ciências do espírito - acaba por desaparecer radicalmente do âmbito da ciência. A ideia moderna de método e o primado absoluto deste sobre as coisas remetem para o esquecimento absoluto todo outro tipo de racionalidade: aquela que não tem tanto em vista o saber útil, mas pelo contrário, a formação humana feita por meio da apropriação das crenças, tradições, das valores e decisões que fundam as comunidades humanas.

Por outras palavras, a partir da Modernidade, a investigação separa-se do ethos, da capacidade de enraizamento e abertura que caracteriza o humano e abre-se ao infinito de uma especialização, comercial ou profissional, cada vez mais apurada. Ora, acontece que, desenraizada do mundo da vida em que apesar de tudo, o homem continua a ser, a viver e a compreender, o caminho da especialização científico-técnica acaba por converter-se numa séria ameaça, que se estende à vida ética e social do homem. Isto é, como nos diz Gadamer, no caminho de um progresso que se despe de toda e qualquer responsabilidade. ${ }^{4}$ Daí o drama do nosso mundo contemporâneo: a formação da nossa consciência social e política não foi capaz de acompanhar o ritmo do desen-

Idem, ibidem, pp. 130-131

Idem, ibidem, pp. 113-114.

Idem, ibidem, pp. 58-59. 
volvimento científico e tecnológico e a eficiência das suas aplicações. Devorados pelo ritmo da eficácia, desaprendemos o verdadeiro significado do discernimento, quer isto dizer, " não só o sentido prático para alcançar determinados fins, como a capacidade para os precisar e a responsabilidade a adoptar perante eles". ${ }^{5}$ Chegámos, no entanto, a uma altura em que percebemos que a simples eficiência não resolve os problemas criados pela sua própria lógica. São os próprios homens de ciência que, na segunda metade do séc. XX, reclamam por uma outra orientação - uma orientação ética - no interior da sua própria ciência. E são as situações de conflito criadas pelos efeitos da, cada vez maior, penetração da tecnociência nos rituais da conduta humana que levantam hoje sérios problemas à filosofia, dando-lhe a ocasião de definir de novo o sentido da sua tarefa.

Digamos que este embaraço começa por se expressar, logo na primeira metade do séc. XX, na reflexão fenomenológica sobre a natureza dos valores, sobre o seu estatuto - epistemológico ou ontológico? - e mais tarde pelo boom da ética e da bioética. Para Gadamer, este é um problema de natureza hermenêutica que, antes de mais, nos faz perguntar: o que é nos dias de hoje provoca o filosofar? A finitude da praxis, responde, que sempre impõe hic et nunc limites ao progresso da ciência.

O que hoje nos dá que pensar é o facto do próprio mundo científico clamar por guias éticos. A medicina, as empresas, os medias exigem a reflexão ética, uma ética para a vida, e não a ética abstracta dos filósofos, e códigos deontológicos que guiem as suas diferentes praxis. Ora, com esta demanda absolutamente inédita de ética, surge justamente a ocasião de melhor concretizar a máxima fenomenológica de um voltar às próprias coisas, ao mundo da vida, agora por meio de uma reinterpretação do humano e tomando como fio condutor a intencionalidade do agir.

Chegou pois a hora de a filosofia compreender o humano por meio do seu agir e, por isso, a necessidade de distinguir o que a tecnociência tem feito esquecer: que o saber fazer (especializado) não é o saber agir.

\section{II}

Tal é a problemática central da filosofia de Gadamer, aquela que o aproxima da Ética de Aristóteles e o faz levantar a questão: haverá alguma possibilidade de reinterpretar hoje a grande herança do saber que se cultivou por si mesmo e da filosofia prática da humanidade clássica? O filósofo não se cansa de nos lembrar que hoje o que nos dá que pensar é a finitude da praxis humana, aquela que a ciência moderna esqueceu e confundiu com a praxis técnica dos experts; que a capacidade humana de meditação ou theoria faz 
parte integrante da praxis; ${ }^{6}$ que à natureza humana pertence uma forma simbólica de praxis que nada tem a ver com uma forma automática de agir pois é, pelo contrário, um tipo de acção que tem como objectivo manter fins remotos a alcançar e que deve sempre escolher ou decidir a favor de algo e contra algo, que a hermenêutica que ele que considera filosófica é uma filosofia prática ${ }^{7}$ e não uma metodologia das ciências humanas; que a filosofia prática implica uma hermenêutica.

O que é então uma filosofia prática, perguntemos, e qual a sua relação com a hermenêutica ou por outras palavras será esta natureza hermenêutica da praxis o que a distingue de uma aplicação puramente pragmática? Analisemos então a questão: No texto "A Hermenêutica como filosofia prática"8 Gadamer começa por se interrogar sobre a razão pela qual a Hermenêutica adquire uma grande actualidade filosófica no séc. XX. Lembra-nos que ela começou por ser uma arte de interpretação, existindo ao lado das artes que permitiam a convivência humana, tais como a Gramática, a Retórica e a Dialéctica: tal como a Retórica, a Hermenêutica indicava uma capacidade natural do homem e significava a aptidão deste para as relações plenamente significativas com os outros homens. ${ }^{9}$ Enquanto arte, a hermenêutica era então em primeiro lugar, um elemento prático da actividade de compreender e de interpretar, e Gadamer refere ainda que a expressão arte (Kunstlehre) tem a sua raiz na tradição aristotélica que hoje se perdeu e na qual existia uma filosofia prática (sive politica) que continuou viva até aos finais do séc. XVIII. Ora, tal tradição formava os quadros sistemáticos de todas as artes, na medida em que todas elas estavam ao serviço da polis.

A própria expressão aristotélica filosofia prática refere tanto a filosofia como a ciência, mas não o tipo de ciência que para os gregos era o modelo do conhecimento teorético, isto é a matemática. ${ }^{10}$ Prática era então todo aquele tipo de ciência que contradizia a filosofia puramente teorética, a qual envolvia a Física ou seja o saber da natureza, a matemática e a teologia (ciência primeira ou metafísica). A filosofia prática partia de um pressuposto que se perdeu com a Modernidade: uma vez que o homem é um ser político, a ciência política era o nível mais elevado da filosofia. Ela não implicava qualquer oposição à ciência; a própria oposição à teoria, que é clara na classificação aristotélica das ciências, não é aqui determinante, como o prova a frase de Aristóteles, segundo a qual "chamamos activo em grande medida àqueles que apenas se determinam através da sua produção intelectual. A própria teoria, como fim em si, era para o filósofo uma praxis de vida.

6 Cf., H.-G.Gadamer, Vernunft im Zeitalter der Wissenschaft. Aufsaetze, Frankfurt, 1976, 62$-65 ; 82-83 ; 123-124$.

7 Idem, ibidem, pp. 108-109.

8 Idem, ibidem, pp. 78-109.

9 Idem, ibidem, p. 78.

${ }^{10}$ Cf. Idem, Ueber die Verborgenheit der Gesundheit, pp. 11-49. 
Claro que tudo isto é para nós hoje muito estranho, uma vez que desde a Modernidade o significado da praxis refere a aplicação do saber útil, com tudo o que esta aplicação tem de massificação, de acomodação e mesmo de irresponsabilidade. ${ }^{11}$ Mas e é bom não esquecê-lo: o campo conceptual originário que determina a palavra e o conceito de praxis nada tem a ver com uma aplicação da ciência; diz, pelo contrário, respeito aos modos de comportamento dos seres vivos, na sua mais ampla generalidade. A praxis, enquanto é a vitalidade ou a qualidade do ser vivo, situa-se entre a actividade e o estar situado, significa a realização vital (energeia) do ser vivo em geral, ao qual corresponde um modo de vida. Ora, o modo de vida do homem é distinto do dos animais pela cidadania, que implica a regra universal e a froairesis, isto é, a capacidade de execução e escolha prévia. Preferir cientemente uma coisa a outra e escolher de forma consciente as possibilidades, tal é a distinção específica do homem, a sua característica singular ${ }^{12}$. A praxis humana não se reduz ao carácter natural de um comportamento, como acontece com os animais; ela é, pelo contrário, constituída pela interacção, que pressupõe a pertença a regras e rituais e a decisão livre, por sua vez conduzida por uma ordem de preferências.

Além disso, de acordo com Aristóteles, a praxis não delimita os seus contornos pela distinção radical face à teoria, mas pelo contrário, face ao fabricar: "A filosofia prática determina-se através da diferença que existe entre o saber prático, daquele que livremente escolhe, e o saber aprendido do especialista, a que Aristóteles chama techné". ${ }^{13}$ Com efeito, a praxis nada tem a ver com as artes de oficina, os saberes pragmáticos ou úteis, que se podem aprender e esquecer ou com as habilidades, por mais que estas sejam essenciais à vida em comunidade. Diz, pelo contrário, respeito àquilo que cabe a cada um enquanto cidadão e àquilo que forma a sua aretê; ela traz à consciência a maior distinção humana, poder submeter-se a regras e ser froairesis ou capacidade de escolha ${ }^{14}$.

Nada é pois mais estranho à praxis do que a eficiência de uma eficácia cuja efectividade é apreciada pela sua utilidade; a praxis dá, pelo contrário, conta do ponto de vista do saber prudente, segundo o qual o homem pode preferir algo a algo e por isso ser responsabilizado. Poder escolher, poder agir e ser imputável, eis as grandes linhas da praxis, que pressupõe então a habitação das grandes narrativas, dos grandes mitos, rituais e ordenações (ethos), que fomentam a coesão social e política em que radica a responsabilidade e a solidariedade do viver em comum.

Então, enquanto a produção, própria da poiesis, artística ou técnica vale apenas pela obra produzida, (que lhe permanece sempre exterior,), a actividade

${ }^{11}$ Cf. Idem, Vernunft im Zeitalter der Wissenschaft. Aufsaetze, p. 60.

${ }^{12}$ Idem, ibidem, pp. 81-82

${ }_{13}$ Idem, ibidem, p. 82.

14 Idem, ibidem. 
prática tem o seu fim em si mesma. A acção não é a produção nem a produção é a acção. Poiesis e praxis são completamente diferentes: a arte (technê) diz respeito à produção e não à acção, no sentido de praxis. O princípio da acção, já vimos, é a escolha livre e esta é fruto do desejo e do logos orientados para um fim: a escolha não pode existir sem a inteligência e o pensamento não pode ser sem a disposição ética. A ciência prática não é nem uma eiência teorética, ao género da matemática, nem um saber útil ou especializado no sentido da poiesis. No entanto, ela é ciência, uma ciência específica : um saber universal, sempre sob condições ${ }^{15}$. Com efeito, baseado numa pertença a costumes, a normas e a tradições, que constituem a rede simbólica originária do agir ético e cidadão, este saber implica sempre uma mediação muito particular entre o desejo e a razão e ainda um entendimento com a situação na qual o ético deve ser recriado em acto.

O mesmo acontece com a Hermenêutica, lembra-nos Gadamer. Enquanto arte do entendimento entre os homens, ela começou, de facto, por ser uma prática da compreensão e interpretação de determinados textos, o bíblico, o jurídico e o clássico. E o seu principal objectivo era a aplicação do sentido do texto às situações concretas, que procuravam entender-se à luz deles. Mas também nesta aplicação não se tratava de compreender primeiro e aplicar depois: com efeito, aqui a própria aplicação não era propriamente uma aplicação, dado que a compreensão Era já a realização em acto do sentido do texto. De outro modo, sem esta realização, não havia compreensão ${ }^{16}$ Exemplos decisivos desta forma de aplicação, em que qualquer coisa é dada que não precede o momento da aplicação são, ao nível da interpretação do texto bíblico, a Reforma protestante e ao nível da Jurisprudência a constante interpretação da lei que está implicada no processo histórico da sua aplicação a cada caso.

O caso da Reforma é paradigmático, na medida em que o seu princípio sacra scriptura sui ipsius interpres tornou-se a origem da nova confissão, que se baseia numa nova hermenêutica do texto. Ao nível da jurisprudência, também não existe interpretação correcta da coisa jurídica, a não ser na chegada à linguagem da própria coisa.

A interpretação justa da lei, nomeadamente, envolve uma mediação da generalidade desta com os casos concretos, que pedem juízo e esta mediação não é uma simples aplicação técnica ou subsunção, mas sim a própria recriação do sentido da lei ou da ideia de direito. Ela procura encontrar o sentido que a lei universal deve ter em cada caso concreto. Também a ruptura criada pelo humanismo, para o qual os grandes clássicos, latinos ou gregos deviam ser apropriados como modelo de uma cultura humana mais elevada, ultrapassou os limites estreitos de uma mera tecnologia da compreensão e correspondeu a

${ }^{16}$ Idem, Hermeneutik I.Wahrheit und Methode 1. Gesammelte Werke I, Tübingen, Mohr,1986, pp. $312-313$. 
um ideal formação humana, isto é, de filosofia prática, neste sentido da praxis como criação em acto.

É justamente no conceito aristotélico de fronesis, a sabedoria prática mediadora entre o ethos e as situações, que Gadamer, e já Heidegger, fundam a nova racionalidade hermenêutica, que tem como objectivo a recriação em acto do sentido do texto A fronesis ou prudência, a sabedoria prática era para Aristóteles, sophia, o eixo crucial da ética e era para os gregos um aspecto fundamental da Filosofia.

O Estagirita define, aliás o papel da fronesis como a capacidade de aplicar, ou recriar, de forma justa, a regra em cada caso. E para assinalar a sua peculiaridade e importância refere-se a três profissões especialmente necessitadas dela: a do político a do juíz e a do médico. Vejamos: o bom médico não é aquele que conhece a teoria sobre a doença do doente, mas aquele que o cura. Para isso, precisa muitas vezes de se distanciar dos manuais e técnicas para interpretar as circunstâncias concretas do doente. Também o juiz e ainda o político precisam de partir, como o médico, de um saber e de uma hermenêutica da experiência prática para poder tomar enfim decisões.

A praxis pressupõe uma racionalidade própria: tal como a techné, parte de uma forma de saber que orienta o agir, mas trata-se num e noutro caso de saberes muito diferentes. O saber da techné é instrumental, uma forma de saber tirar proveito da natureza, é um saber que primeiro se aprende e depois se aplica automaticamente. É um saber para poder. Ora quanto ao saber prático, o seu elemento fundamental é, em Aristóteles, o desejo e a organização deste numa atitude firme, a formação da virtude ou, por outras palavras, o desejo natural acordado, confirmado e corrigido pela educação e pelo hábito, que dele fazem uma disposição estável. Mas atenção, não basta dizer que a virtude deve ter sido exercida e formada pela educação. É preciso precisar: é necessário uma boa educação.

Esta é a forma de saber que conduz a praxis ética, cuja tarefa é mediar uma situação concreta pelas exigências éticas mais gerais. Aqui, tal como na hermenêutica, não estamos diante de uma coisa que se trata de constatar, manipular e conhecer, mas estamos completamente investidos pelo significado do ethos e pelo que deve ser que deve ser feito, hic et nunc. Estas duas formas de saber não são puramente teoréticas, dizem respeito, como já o dissemos, à experiência, embora não tenham nada em comum com o saber que dirige a experiência técnica.

Praxis e techné, convenhamos, têm em comum a necessidade, precisam então as duas de uma forma de um saber que as guie. No entanto, lembra-nos Gadamer, o saber dos artesãos não é, já desde o tempo de Sócrates, o saber que faz o homem enquanto cidadão. ${ }^{17}$ Praxis e techné implicam as duas uma forma de aplicação do saber a cada situação concreta, mas a aplicação é nos 
dois casos totalmente diferente. Vejamos: o que sabe produzir algo, sabe-o para si e fá-lo sempre que se surjam as possibilidades de o fazer. Ao passo que aquele que deve tomar decisões morais também aprendeu algo; por educação e procedência está determinado de tal modo que sabe em geral o que é correcto. A tarefa da decisão moral é no entanto a de acertar com o que é adequado numa situação concreta, isto é, a de ver o que nela é correcto e possível de fazer, o que implica uma hermenêutica da situação.

Mas o que é que isto quer dizer? Que no saber ético não se trata apenas de conhecer racionalmente uma norma ideal para em seguida a aplicar. Pelo contrário, aquele que sabe deve concretizar na sua situação particular da acção a sua própria pertença à validade normativa do ethos dominante - uma norme aberta -, isto é ao fundo normativo no qual foi educado. Sem esta concretização da norme ela própria não tem sentido, o que implica que a concretude das situações intervém enquano aplicação, escolha preferencial, ou diferenciação no próprio ser da norma. Esta realiza-se somente na realidade concreta de cada caso.

Concluindo: a aplicação hermenêutica, tal como Gadamer a pensa, pressupõe a praxis como a criação em acto do universal pré-compreendido, um universal que não é de modo nenhum de ordem técnica ou lógica.. É, pelo contrário, simbólico, um esquema de acção que possui margens difusas, tal como acontece com o texto ou com a lei. Está referido à exigência da sua aplicação hermenêutica à situação concreta da praxis dialógica.

Pensar a praxis exige pois que se reconheça, em primeiro lugar, a simbólica da acção, quer dizer, o conjunto dos rituais e regras que permitem a com-vivência e, em segundo lugar, a ordem das preferências, a froairesis que permite passar à decisão. Neste sentido a praxis tem uma estrutura hermenêtica, parte de um saber prévio que, precisa de ser explicitado por meio de uma escolha.

Tal é a importância da reflexão gadameriana: a praxis de cunho ético e político tem uma estrutura hermenêutica.

\section{III}

Há então uma pois uma correspondência clara entre o saber ético e o hermenêutico; os dois são uma forma de saber orientado para a praxis, que nada tem de comum com a praxis automatizada dos nossos dias. Necessário é pois explicitar as suas grandes diferenças, recorrendo desde logo a Aristóteles, que os distinguiu deste modo: a) em primeiro lugar, lembra-nos, uma técnica aprende-se e pode ser esquecida. Ora, o saber ético nem se aprende nem se esquece, como o do profissional, (que pode recusa-lo, perder o jeito e escolher outro). Porquê? Porque o sujeito ético caracteriza-se pelo facto de estar já irremediavelmente lançado em situação de agir, quer isto dizer, que "está já 
sempre obrigado a possuir um saber ético e a aplicá-lo segundo as exigências da sua situação concreta". ${ }^{18} \mathrm{O}$ saber ético não se aplica de maneira idêntica à do saber técnico, dado que ele não é propriedade do sujeito ético, como é o técnico.

De facto, se é verdade que a imagem que todo o homem forma do que seja o justo, o injusto, a coragem e a solidariedade, é constituída por ideias directrizes (aprendidas sobretudo na literatura), há uma diferença radical entre estas ideias e aquelas que o artesão aplica. É que o que é justo é totalmente relativo à situação ética em que nos encontramos: quer dizer, não se pode descrever de modo abstracto que acções são justas e quais as que não são. Mesmo que se diga que o que é recto e justo se define por meio de leis ou regras de comportamento não codificadas, mas válidas para todos, é apenas na aplicação da norma à situação concreta que os contornos da norma se definem

Quando aplicamos uma lei, pode acontecer que sejamos obrigados a atenuar, por via das características de uma situação concreta, o rigor dessa lei. E atenuar o rigor da norma não é não aplicar o direito que a lei exprime, nem tão pouco permitir um laxismo ilegítimo". ${ }^{19}$ Atenuar o rigor de uma lei não significa renunciar-lhe, mas saber que sem essa atenuação não haveria propriamente justiça. O mesmo não acontece com a techne do artesão: é que o molde é completo e a lei é sempre insuficiente, esquemática " não em razão de um defeito intrínseco, mas porque o mundo, enquanto lugar das nossas acções, é sempre imperfeito por relação à ordem ideal visada pelas leis". ${ }^{20}$

b) em segundo lugar, enquanto a actividade técnica tem antecipadamente consciência dos meios justos que realizam um determinado fim, na fronesis os próprios fins nunca se dão como estando perfeitamente determinados e os meios devem ser sempre pesados de novo pelo sujeito. O domínio ético é aquele "onde o saber técnico cede o lugar à deliberação e à reflexão". ${ }^{21} \mathrm{O}$ saber ético apenas se cumpre na situação concreta, "hic et nunc." Chamamos saber ético ao que une, de uma forma original, os nossos conhecimentos dos fins e dos meios e se opõe precisamente desse ponto de vista, a um saber puramente técnico. Deixa pois de ter sentido, desde logo, distinguir saber e experiência, pois o saber ético é em si mesmo já uma experiência".22

c) Em terceiro lugar, o saber ético pressupõe uma forma de consciência de si absolutamente diferente da consciência técnica, na medida em que implica um novo momento, a compreensão ou sunesis ${ }^{23}$ isto é a possibilidade de nos colocarmos na situação em que o outro deve agir. Também neste caso o saber não é geral, mas exige uma realização concreta, que supõe o laço comu-

18 Idem, Le problème de la conscience historique, Paris, Louvain, Nauwelaerts, 1963, p. 56

19 Idem, ibidem, p. 58.

20 Idem, ibidem.

21 Idem, ibidem, p. 60

22 Idem, ibidem, pp 61-62.

23 Idem, ibidem, p, 62. 
nitário que me permite viver em harmonia com o outro. Aliás, o facto de viver em harmonia com alguém não manifesta todo o seu alcance ético senão pelo fenómeno da 'compreensão', que, nada tem a ver com o simples conhecimento técnico do psicólogo ou do expert, mas se concretiza no fenómeno do conselho moral, válido entre amigos. Só a pertença dos amigos a uma mesma causa justa permite o discernimento da situação do outro e a tolerância ou indulgência que daí resultam. "Aristóteles assinala, com efeito o carácter puramente virtuoso do saber ético. E para lhe dar ainda mais relevo, descreve a forma degenerada da fronesis que caracteriza o [...] homem, que por meio da sua inteligência subtil, dá a volta a todas as situações para sua vantagem. A sua oposição à fronesis propriamente dita é evidente: [...] este homem abusa do seu poder sem qualquer consideração ética. E não é por acaso que o nome deste homem que vence, não importa que situação, se traduz, precisamente por temível. Nada é mais assustador do que um génio organizado, e que não tem em conta o bem e o mal", ${ }^{24}$

Concluindo: a análise aristotélica do saber ético revela-nos a fronesis como um tipo de conhecimento hermenêutico que realiza em acto o previamente conhecido, por meio de uma decisão que constitui por sua vez o núcleo da aplicação. Como vimos, não se trata aqui de uma aplicação puramente técnica ou operatória. A própria compreensão é aplicação ou por outras palavras a aplicação intervém na compreensão, tal como aconteceu sempre na hermenêutica jurídica e protestante. O núcleo fundamental deste tipo de aplicação comum à Hermenêutica e à Ética, em sentido aristotélico, caracteriza-se pelo problema existencial de uma praxis tocada e enquadrada pelo poder formador e configurador da palavra, dos costumes ou do texto. O que implica que compreender o texto, de forma adequada, isto é, de acordo com a sua ambição de verdade significa, quer se trate da mensagem da salvação, do ethos ou da lei, compreender o texto de modo novo e diferente em cada instante, quer dizer em cada situação concreta. Compreender é aqui executar, aplicar, uma tarefa prática, de um modo tal que não há uma distinção entre estes dois momentos só pode compreender quem partilha, explicitando-o, o sentido da lei, do ethos ou do texto, sabendo respeitá-lo sem trair as exigências da sua situação concreta. "Quando o juiz tenta adequar a lei transmitida às necessidades do presente tem claramente a intenção de resolver uma tarefa prática. $\mathrm{O}$ que de modo algum quer dizer que a sua interpretação da lei seja uma tradução arbitrária. Também no seu caso, compreender e interpretar significa conhecer e reconhecer um sentido vigente. Ele tentará responder à ideia jurídica da lei, mediando-a com o presente", ${ }^{25}$ isto é, admitindo que as circunstâncias mudaram e que por consequência, a função normativa da lei tem de se determinar de novo. ${ }^{26} \mathrm{~A}$

24 Idem, ibidem, p.63.

25 Idem, Hermeneutik I. Wahrheit und Methode 1. Gesammelte Werke I, p. 333.

${ }^{26}$ Idem, ibidem, p. 332. 
aplicação da lei é, neste sentido, criadora de direito, encontra o sentido que ele pode ter hoje, isto é, explicita o seu sentido correcto em cada caso.

Algo de semelhante acontece com a tradição literária e poética. Também nestes dois casos quem interpreta não admira apenas a força poética, a fantasia e a arte da expressão. Admira sobretudo a verdade superior que lhe fala, a partir dela. Sente-se intimado, não deixa as coisas tal como estão, sofre o efeito histórico de, toma decisões. A sua compreensão é uma forma renovada de realizar hic et nunc o referente do texto e tem o carácter de um acontecimento. ${ }^{27}$

Nisto reside a semelhança entre o texto, a lei e o universal ético: representam uma forma de universal que não é nem técnico nem lógico. Não é puramente constringente; é pelo contrário um esquema de acção; tem margens pouco claras, que só em cada situação ganha contornos, pois não pode abranger todas as situações. Neste sentido, lembra-nos Gadamer, actualizando a mensagem de Aristóteles, a ética não pode ser senão uma ética prática, isto é, a elucidação dialógica do ethos determinante.

E esta realiza-se originariamente na clarificação da situação que exige uma decisão ${ }^{28}$, quer isto dizer, é sempre um risco que não permite a simples aplicação automática de um saber geral de regras claras. O mesmo acontece com a compreensão hermenêutica que, perante um texto, está muito mais interessada nas perguntas do que nas respostas. Por isso, ela nunca conclui, está sempre a caminho, é algo mais do que a aplicação artificial de uma capacidade, implica sempre que por meio dela se alcance uma auto compreensão diferente, mais ampla e profunda do que a anterior. Á grande tradição da filosofia prática, lembra-nos o filósofo, sobrevive numa hermenêutica deste tipo. (que tem consciência das suas implicações filosóficas. (Rec, p.76). E uma hermenêutica deste tipo, é aquela que reconhece que compreender é sempre interpretar e interpretar é aplicar.

É o diálogo o modelo deste tipo de compreensão que é aplicação, mas não em sentido não tecnológico.

Também P. Ricoeur sabe que a praxis concreta do humano nada tem a ver com praxis técnica, a produção e que pensá-la exige a mediação de uma simbólica ${ }^{29}$ e de uma mítica concreta. É com A simbólica do mal que o filósofo inicia a sua Hermenêutica, como filosofia da praxis ético e política do ser humano. Filosofia esta que exige uma via longa de reflexões sobre a semântica da acção, que culminarão na obra Temps et récit. ${ }^{30} \mathrm{~A}$ ideia de fundo é esta: sem a mimesis, realizada por meio do muthos narrativo, a praxis ética e polí-

Idem, ibidem, pp. 343-344.

28 Idem, Langage et vérité, trad, Paris, Gallimard, 1995, p. 214.

29 P. Ricoeur, Philosophie de la volonté. F initude et culpabilité II La symbolique du mal. Paris, Aubier, 1960.

${ }^{30} \mathrm{P}$. Ricoeur, Temps et récit I, Paris, Seuil, 1983 ; Idem, Temps et récit, II. Le temps raconté, Paris Seuil, 1984;-Idem, Temps et récit, III, Le Temps raconté, 1985. 
tica, de natureza temporal, não se diz nem se conhece. São narrativas as suas categorias e é hermenêutica a sua sabedoria que, para além de uma compreensão da qualidade do mundo vivido da ética, entra em diálogo com as instituições que realizam a justiça e mantêm a ordem pública.

\begin{abstract}
A presente comunicação procura pensar a ideia de hermenêutica como filosofia prática, a partir das semelhanças que Gadamer estabelece entre a racionalidade hermenêutica e a fronesis aristotélica. A ideia chave é esta: o núcleo fundamental da razão hermenêutica é a unidade de compreensão, interpretação e aplicação; a aplicação é o cerne da racionalidade hermenêutica, que sempre foi suscitada por casos de tensão entre situações singulares de vida e textos ou leis com sentido universal, que melhor permitem entendê-las. Neste sentido, a tarefa hermenêutica é semelhante à da ética aristotélica: medir uma situação concreta à luz das exigências éticas mais gerais. Tal é de facto a condição da praxis ética e política do ser humano, aquela que hoje é absolutamente necessário pensar face à inflação contemporânea de uma praxis guiada por mecanismos automáticos de índole técnica. Quer isto dizer que é necessário hoje clarificar absolutamente o que distingue a praxis conduzida pela technê da praxis ética e política como condição da liberdade humana. Segundo Gadamer, esta tem uma natureza hermenêutica que urge clarificar, pois, ela parte sempre de regras, tradições, leis que são recriadas em acto na situação hermenêutica da sua aplicação.

Aplicação hermenêutica e froairesis têm uma estrutura semelhante que é necessário perceber pois também a praxis técnica é uma forma de aplicação, embora de natureza bem diferente.

P. Ricoeur sabe também que a praxis concreta do ser humano nada tem de semelhante à praxis técnica, a produção e que pensá-la exige a mediação de uma simbólica e de uma mítica concreta.
\end{abstract}

